\title{
O coordenador pedagógico subsumido à política nacional de alfabetização no entretempo 2009 a 2019: uma tela de Penélope?
}

\author{
The pedagogical coordinator subsumed under the national literacy policy in the \\ temporal cut off 2009-2019: a Penelope's canvas?
}

Silvia Cristiane Alfonso Viédes Discente do Programa de Pós-Graduação em Educação da Universidade Federal da Grande Dourados Doutorado, participante do Grupo de Estudos e Pesquisa Estado, Política e Gestão da Educação (GEPGE), Dourados - MS, Brasil. silviedes@hotmail.com

\begin{abstract}
Maria Alice de Miranda Aranda Docente do Programa de Pós-Graduação em Educação da Universidade Federal da Grande Dourados Mestrado e Doutorado (PPGEDU/UFGD) e Pós- Doutora em Educação pelo Programa Nacional de PósDoutorado/Coordenação de Aperfeiçoamento de Pessoal de Nível Superior (PNPD/CAPES) na Universidade Federal de Uberlândia (UFU), Dourados - MS, Brasil. mariaaranda@ufgd.edu.br

Cristina Pires Dias Lins Mestra em Educação pelo Programa de Pós-Graduação em Educação da Universidade Federal da Grande Dourados, participante do Grupo de Estudos e Pesquisa Estado, Política e Gestão da Educação (GEPGE), professora efetiva da Escola Municipal Neil Fioravanti- Unidade CAIC, Dourados - MS, Brasil. cristinapdl@yahoo.com.br
\end{abstract}

\begin{abstract}
Resumo: $O$ objeto dessa pesquisa recai sobre a função do coordenador pedagógico na política educacional em contexto da alfabetização. O objetivo é analisar, em analogia à metáfora da tela de Penélope, como a política supramencionada prescreve o papel do coordenador pedagógico, no recorte temporal 2009-2019. O modelo teórico utilizado fundamenta-se pelo materialismo histórico dialético. A abordagem metodológica é de cunho qualitativo, com análise bibliográfica e documental. Constata-se que a política em epígrafe, reproduz, ao longo dos Programas, a função do coordenador pedagógico atrelada a ação burocrática, seja na implementação ou pela atribuição da responsabilidade dos sistemas destinados a gerir o processo alfabetizador, o que favorece condições inadequadas de trabalho, incoerência e falta de objetividade na função do coordenador pedagógico, ou seja, na exploração dessa classe, que constitui no âmbito da Política Nacional de Alfabetização, uma tela de Penélope.
\end{abstract}

Palavras-chave: Coordenador pedagógico. Política nacional de alfabetização. Processo alfabetizador.

Abstract: The purpose of this research rests on the role of the pedagogical coordinator in educational policy in the context of literacy. The objective is to analyze, in analogy to the Penélope canvas metaphor, how the aforementioned policy prescribes the role of the pedagogical coordinator, in the temporal cut-off 2009-2019. The theoretical model used is based on dialectical historical materialism. The methodological approach is qualitative, with bibliographical and documentary analysis. It can be seen that the above policy reproduces throughout the Programs the role of the pedagogical coordinator linked to bureaucratic action, either in the implementation or by assigning responsibility for the systems designed to manage the literacy process, which favors inadequate working conditions, inconsistency and lack of objectivity in the role of 
the pedagogical coordinator, that is, in the exploitation of this class, which constitutes, within the framework of the National Literacy Policy, a Penelope's canvas.

Key-words: Pedagogical coordinator. National Literacy Policy. Alphabetizing process.

\section{Introdução}

O escopo da Política Nacional de Alfabetização da criança brasileira, instituiu-se ao longo da última década, por Programas de governo, definidos por Palumbo (1989) como atividades que têm finalidades específicas, implementadas por agências denominadas de unidades governamentais que são responsáveis pela formulação e implementação das políticas.

Nesse basilar, apreende-se que a função do coordenador pedagógico, deve estar assegurada nos discursos dos documentos que legitimam os Programas, considerando que esse profissional é “[...] sujeito do processo educativo que tem o compromisso de buscar garantir o direito a educação de qualidade para todos no âmbito escolar" (VARGAS, ARANDA e DAN, 2014, p. 03).

O estudo proposto sobre a função do coordenador pedagógico consubstanciado à prescrição pela política supramencionada, não comunga com o ideário do viés regulatório e manipulador de cristalizar ou manipular as atividades do coordenador pedagógico, mas desvelar qual tratamento é anunciado nessa diretriz que favorece a composição de sua própria identidade, como preconiza estudos de Placco $(2010,2011)$ e Geglio (2011).

Com base no entendimento da Police Cycle de Palumbo (1989), a política abrange cinco fases compreendidas como agenda, formulação, implementação, avaliação e término (Ibid) e, nesse sentido, o presente estudo centra-se na fase da formulação, a fim de investigar os Programas voltados à alfabetização da criança brasileira no período 2009-2019, em interface à menção e/ou omissão do coordenador pedagógico, concernentes aos discursos formalizados.

Nessa conjectura, para implementar tal política em contexto da alfabetização, o coordenador pedagógico precisa estar fundamentado em relação à “[...] concepção de sociedade, de educação, de ser humano, de gestão, de planejamento e currículo escolar, de avaliação" (Ibid), categorias norteadoras do processo alfabetizador em questão.

\section{O coordenador pedagógico consubstanciado aos Programas em contexto de alfabetização da criança}

No cenário da política educativa em contexto de alfabetização que abarca a década de 2009-2019, constata-se que foram instituídos três Programas federais, a saber: o Pró-letramento, 
o Pacto Nacional pela Alfabetização na Idade Certa (Pnaic) e o Programa Mais Alfabetização (PMAlfa); não obstante, tem-se anunciado na atualidade governamental, o Programa Alfabetização Acima de Tudo, porém, até o fechamento dessa pesquisa, o mesmo não foi oficializado.

\subsection{Programa Pró-letramento}

O Pró-letramento foi instituído em 2005 no governo de Luiz Inácio Lula da Silva e sofreu reedição no mesmo governo. O principal objetivo circundou a formação continuada de professores, com o propósito de elevar a qualidade da aprendizagem em contexto de alfabetização relacionadas às áreas de linguagem e matemática, bem como criar situações de incentivo a reflexão e construção do conhecimento (BRASIL, 2007, p. 02).

Dispôs cinco atores responsáveis pela sua implementação: o Coordenador Geral do Programa juntamente com o profissional vinculado a universidade parceira; Formador vinculado a Universidade formadora cabendo-lhe o desempenho de formar os orientadores de estudos; o Coordenador Administrativo do Programa, incumbido de organizá-lo à nível municipal e articular a Instituição de Ensino Superior (IES); Orientador de Estudos, professor efetivo municipal, cabendo-lhe a participação na formação junto à Universidade sendo este posteriormente, articulador entre a Universidade e os cursistas; e o Professor Cursista $\left(1^{\mathrm{a}}\right.$ a $4^{\mathrm{a}}$ série ou $1^{\circ}$ ao $5^{\circ}$ ano) que deveria estar lecionando e estar inscrito no Programa.

Um ponto destacável é o pioneirismo do Programa Pró-letramento voltar-se com exclusividade ao atendimento do processo alfabetizador da criança, assim como pela primeira vez firma-se a concessão de bolsas aos atores implementadores.

O formato do Programa ocorreu pela formação continuada para os cursistas em dois momentos, divididos em 84 horas presenciais e 36 horas na modalidade à distância, desdobrando-se no total de 120 horas.

Em relação aos materiais disponibilizados para formação, foram dispostos em fascículos que abordaram os mais diversos temas ligados à alfabetização, letramento, números naturais envolvendo planejamento, organização do tempo pedagógico, uso dos espaços, ludicidade, uso do livro didático, modos de falar e escrever, entre outros (Ibid). Houve também materiais videográficos que foram entregues em kits para os tutores, que auxiliaram nos momentos de estudos à distância. 
Em análise ao documento, verificou-se que nas linhas e entrelinhas do Programa não se faz menção ao coordenador pedagógico como sujeito integrante das formações, tampouco como implementador do processo alfabetizador. Pontua-se que o Programa encontra-se desativo desde o ano 2012.

\title{
2. 2 Programa Pacto Nacional pela Alfabetização na Idade Certa (Pnaic)
}

O Pnaic, estabelecido em 2012 sob o governo Dilma Vana Roussef, teve por objetivo a alfabetização da criança na 'idade certa', que para o Programa preconiza os oito anos, ao final do terceiro ano do ensino fundamental, tanto em Língua Portuguesa quanto em Matemática (BRASIL, 2012a).

Contudo, “[...] não existe 'idade certa' para ser alfabetizado" (LINS, 2018, p. 19); mediante que a alfabetização é "[...] um processo permanente que se estenderia por toda a vida e que não se esgotaria na aprendizagem da leitura e escrita [...]" (SOARES, 2011, p. 15). Razão pela qual se considera que no processo alfabetizador cada criança tem o seu momento próprio de aquisição de aprendizagem.

O formato do Pnaic se desdobrou em quatro eixos, dispostos no Artigo $6^{\circ}$ da Portaria $n^{\circ}$ 867/2012, quais sejam: formação continuada dos professores; materiais didáticos, tecnologias e literatura educacionais; avaliação e por fim, gestão, controle e mobilização social” (BRASIL 2012a).

Quanto aos recursos, estão dispostos no Artigo $8^{\circ}$ e consistem em:

\begin{abstract}
I- livros didáticos de $1^{\circ}, 2^{\circ}$ e $3^{\circ}$ anos do ensino fundamental e respectivos manuais do professor a serem distribuídos pelo Programa Nacional do Livro Didático - PNLD; II obras pedagógicas complementares aos livros didáticos distribuídos pelo Programa Nacional do Livro Didático - Obras Complementares; III - jogos pedagógicos para apoio à alfabetização; IV - obras de referência, de literatura e de pesquisa distribuídas pelo Programa Nacional Biblioteca na Escola - PNBE; V - obras de apoio pedagógico aos professores, distribuídas por meio do PNBE; VI - tecnologias educacionais de apoio à alfabetização (BRASIL, 2012b, p. 18).
\end{abstract}

Além disso, o Pnaic articula-se a outros Programas, como o Programa Nacional do Livro Didático e Programa Nacional Biblioteca na Escola, no sentido de aquisição de acervos literários, jogos pedagógicos, obras de apoio ao docente e tecnologias educacionais.

A formação continuada, iniciou-se em 2013 tendo como público alvo os professores alfabetizadores com a carga horária se 120 horas. A esses e aos demais integrantes do Pnaic foram concedidos bolsas. 
Nesse referido ano, os coordenadores pedagógicos não foram formalmente inclusos na formação. A legislação do Programa assegurou que poderiam participar desde que estivessem atuando na escola, como orientador de estudo ou de professor alfabetizador, se estivesse lecionando (BRASIL, 2012b), ou seja, a coordenação pedagógica poderia proferir a formação continuada ou ser cursista na condição de professor alfabetizador.

O coordenador pedagógico foi oficialmente integrado ao Pnaic em 2016, (BRASIL, 2016b) pela participação dos coordenadores pedagógicos que estivessem ligados à alfabetização nas escolas da rede pública (BRASIL, 2016a).

O Pnaic concedeu bolsas aos coordenadores pedagógicos e apontou que além de participar das formações as atribuições específicas, detinham-se em " [...] organizar o ambiente da escola, criando um clima propício à alfabetização, à cooperação e ao convívio; acompanhar o progresso da aprendizagem das turmas da sua escola; e auxiliar os professores na definição de estratégias pedagógicas [...]” (BRASIL, 2016b, p. 12).

Apresentou também o Boletim n $n^{\circ}$ 01/2016 com propostas destinadas a esse profissional, orientando-o antes mesmo de iniciar a formação no Programa a:

[...] analisar os Boletins da ANA 2013 e 2014 [...]; analisar o desempenho das crianças na Prova Brasil [...] avaliando possíveis impactos do Pnaic [...] registrar quais foram os avanços obtidos pelas crianças [...] organizar os grupos que precisem de apoio pedagógico diferenciado e estimular o progresso e o desenvolvimento de novas competências [...] organizar, nas salas-de-aula, na biblioteca escolar e nos espaços comuns da escola um ambiente motivador para a Leitura, a Escrita e a Matemática [...]; analisar se os professores mantêm uma rotina diária de situações didáticas que, segundo pesquisas, são essenciais para o sucesso na alfabetização [...]; relacionar os materiais didáticos já disponibilizados pelo MEC (PNBE, Projeto Trilhas, etc.) e outros oferecidos pelas redes públicas do estado ou município, colocando-os em lugar de fácil acesso para alunos e professores; [...] definir estratégias, junto com os professores, para ampliar a quantidade de acervo literário [...]; apresentar plano para manter o laboratório de informática e a biblioteca [...]; apresentar projeto de comunicação às famílias, pedindo-lhes que incentivem as atividades em casa, inclusive nos fins de semana [...]; avaliar se a escola oferece um ambiente lúdico e motivador de novos aprendizados [...] que preparam o indivíduo para ser, viver e conviver no século XXI (BRASIL, 2016c).

Coube-lhe a função desde a análise de provas externas em larga escala, perpassando pelo estímulo no alcance às competências das crianças, organização de materiais, exploração dos diversos espaços físicos da escola, definição de estratégias e a busca da parceria com as às famílias no incentivo das proposições do Programa supracitados serem realizados.

No sentido de propiciar o acompanhamento e monitoramento das ações realizadas no campo das formações, foi instituído o módulo Sispacto, que integrou o Sistema Integrado de Monitoramento, Execução e Controle (Simec), cujo acesso para os cursistas consistia no cumprimento de tarefas ligadas aos conteúdos discutidos nas formações, traçar o perfil das 
crianças inseridas no processo alfabetizador e descrever as práticas pedagógicas realizadas no universo escolar.

Em 2017, mesmo que os professores alfabetizadores e coordenadores pedagógicos, embora apareçam no organograma, não lhes foram mais concedidas as bolsas, que em 2016 eram de $\mathrm{R} \$ 200,00$ (duzentos reais) (LINS, 2018).

Nesse período, a Avaliação Nacional da Alfabetização (ANA) demonstrou os índices estagnados sobre a alfabetização, fragilizando a operacionalização do Programa pelo apontamento da insuficiência em leitura, escrita e matemática (BRASIL, 2018a).

O Pnaic desenvolveu seu último ciclo de formação no ano de 2018 e, em relação à participação do coordenador pedagógico, houve um avanço no quesito formulação do Pacto em relação ao Pró-letramento, considerando que esse profissional passa a ser parte integrante dos discursos de implementação do processo alfabetizador.

\section{3 Programa Mais Alfabetização (PMAlfa)}

O PMAlfa foi instituído em 2018, sob o governo de Michel Miguel Elias Temer Lulia, inicialmente pela Portaria $\mathrm{n}^{\circ}$ 04, lançada em janeiro e revogada no mês subsequente pela Portaria n 142 (BRASIL, 2018a, 2018b). Justifica sua implantação pelo viés dos Programas anteriores, ao citar a insatisfação no tocante ao identificador de crianças não alfabetizadas, conforme a Avaliação Nacional de Aprendizagem (ANA). Mister afirmar que a Portaria $n^{\circ}$ 4/2018 foi revogada pela Portaria no 142, de 22 de fevereiro de 2018 (BRASIL, 2018c).

O PMAlfa dispôs por objetivo fortalecer e apoiar as escolas públicas no processo alfabetizador da criança, matriculada no primeiro e segundo ano do ensino fundamental (BRASIL, 2018c).

O formato do Programa é pautado na capacitação e integração do profissional denominado assistente de alfabetização aos demais profissionais, como os docentes alfabetizadores e técnicos (Ibid).

A nomenclatura "coordenador pedagógico" não aparece nas linhas da Portaria no 142/2018, contudo, aparece nas entrelinhas subtendidas no artigo $7^{\circ}$ ao dispor que cabe ao MEC qualificar os profissionais envolvidos com o processo alfabetizador, entre os quais estão os gestores (BRASIL, 2018a). 
Entretanto, o Manual Operacional do Sistema de Orientação Pedagógica e Monitoramento, prescreve a coordenação pedagógica como ator relacionado à implementação do Programa, responsável por:

[...] orientar, apoiar e acompanhar com prioridade o trabalho do professor alfabetizador e do assistente de alfabetização; participar da seleção do assistente de alfabetização, privilegiando a qualidade técnica; por acompanhar a evolução da aprendizagem dos alunos de $1^{\circ}$ ano e de $2^{\circ}$ ano do ensino fundamental regular; por lançar e atualizar os dados de execução do Programa no sistema de acompanhamento e monitoramento específico; e por participar das estratégias de formação no âmbito do Programa (BRASIL, 2018b, p. 11).

É notável que no bojo do PMAlfa caiba ao coordenador pedagógico a função executora de selecionar o assistente de alfabetização, que atuará junto ao professor na sala do ensino regular. Deve apoiar, bem como, acompanhar o desenvolvimento do Programa, a aprendizagem das crianças do $1^{\circ}$ e $2^{\circ}$ ano. Além de participar das capacitações, conforme citado anteriormente, este também é responsável em contribuir com estratégias para formação do desenvolvimento profissional.

Em análise do Pnaic ao PMAlfa, os avanços consistiram no quesito de integração do profissional Assistente de alfabetização, no entanto, apesar de ser firmada a parceria entre ambos (BRASIL, 2018c), em 2018 não foi realizada capacitações para os profissionais do corpus escolar envolvidos com o processo alfabetizador da criança, sejam professores, assistentes, administrativos ou gestores.

Como preconiza o Ofício-Circular n5/2019/COEF/DICEI/SEB/SEB-MEC (BRASIL, 2019b), foi autorizada a reabertura do ciclo 2019 do PMAlfa para as escolas que participaram do Programa em 2018 e que realizaram a confirmação de adesão em 2019.

Com isso, questiona-se quão intensamente a reabertura do PMAlfa como Programa de governo versará seu diálogo consoante ao exposto na Política Nacional de Alfabetização da atualidade, que carrega como uma das metas prioritárias de governo o Programa Alfabetização Acima de Tudo, evidenciado a seguir.

\subsection{Programa Alfabetização Acima de Tudo}

O lançamento das Metas Nacionais Prioritárias do presidente Jair Messias Bolsonaro, em referência à agenda de 100 dias de governo, traz 35 ações alinhadas aos ministérios, alicerçadas em dois critérios: efetividade de entrega das prioridades nacionais e considerável impacto social e, nesse sentido, vincula-se ao MEC a Ação 12, como uma das metas prioritárias: 
Ação 12 Alfabetização Acima de Tudo: Lançamento de um programa nacional de definição de soluções didáticas e pedagógicas para alfabetização, com a proposição de método para redução do analfabetismo a partir de evidências científicas. (BRASIL, 2019a, p. 5).

O governo federal, por meio do Decreto no 9.765 , estabelece a Política Nacional de Alfabetização, que em seu Art. $1^{\circ}$, "implementará programas e ações voltados à promoção da alfabetização baseadas em evidências científicas” (BRASIL, 2019c, p.1).

Com relação ao coordenador pedagógico, no capítulo IV, Art. $7^{\circ}$, inciso V, atribui como agentes envolvidos na política supracitada os gestores escolares, porém, ao fechamento dessa pesquisa, nada foi publicado com relação ao Programa priorizado como Meta Nacional, tampouco documentos orientadores que possam envolver o coordenador pedagógico.

\subsection{O coordenador pedagógico e a política nacional de alfabetização em analogia à tela de Penélope}

Como preconiza Bulfinch (2018), Penélope era filha de príncipe espartano, Icário que, após casar-se com Ulisses, não desfrutou mais de dois anos de união quando se separaram, em razão da participação de Ulisses na Guerra de Troia e, pela longa ausência do amado, surgiu à heroína inúmeros pretendentes; porém, na esperança do retorno de seu amado, alegou empenho em tecer a tela para o funeral de seu sogro Laertes, com o compromisso de escolher seu pretendente assim que concluísse a obra.

Durante o dia, Penélope trabalhava na composição da tela, contudo, ao anoitecer, desfazia toda sua obra e assim o fez por dez anos, até que foi descoberta e, diante dessa interlocução, é pertinente o destaque para quatro elementos em analogia ao pressuposto pela pesquisa, quais sejam: o sujeito, a ação, o objeto e o motivo gerador da ação.

Sobre o sujeito, encontra-se em Penélope a própria política educacional em contexto de alfabetização, articulada à ação aliada pelo entretempo de uma década; ao passo que Penélope designa para a composição da tela, um tempo para construir/descontruir seu objeto, o que esperar da Política supramencionada para a função do coordenador pedagógico?

Nesse sentido, o objeto em questão é a tela que, para essa pesquisa, trata-se do coordenador pedagógico, o fazer-desfazer desse profissional na política em contexto de alfabetização, num mister de reinventar-se e reconstruir-se, Programa-pós-Programa.

Como preconiza Marx e Engels, (1989), o coordenador pedagógico é um objeto de exploração da política em epígrafe, no qual: 
[...] torna- se um simples acessório da máquina. Só lhe exige o gesto mais simples, mais monótono, mais fácil de aprender. Portanto, os custos que o operário gera limitam-se aproximadamente apenas aos meios de subsistência de que necessita para manter-se e reproduzir-se. (MARX e ENGELS, 1989, p. 35).

Busca-se, em analogia à metáfora, o motivo que gera a atuação de Penélope, a procrastinação do tempo, na espera de algo que merece duas análises: em sentido amplo, da constituição da política supramencionada e em sentido estrito, da função do coordenador pedagógico desenhada nessa Política.

Em sentido amplo, constante à formulação de um Programa consubstanciado à Política educacional em contexto de alfabetização, minimamente deve estar imbricada à qualidade, em atendimento a cinco dimensões que cercam a alfabetização, quais sejam: os níveis de espaço social (dimensão socioeconômica e cultural da criança), níveis do Estado (dimensão dos direitos), obrigações e garantias, níveis de Sistema (condições para oferta do ensino), nível de escola (gestão e organização do trabalho escolar), nível do professor: formação, profissionalização e ação pedagógica e o nível da criança (acesso e permanência), preconizadas por Dourado (2007).

O que historicamente acontece com a política supramencionada é a inconsistência em sua formulação: os Programas analisados centram-se na lógica de formação dos professores, sem alinhamento às demais dimensões requeridas pela qualidade da alfabetização oferecida, pressuposta pelo Pró-Letramento, Pnaic, PMAlfa e Decreto em vigência da Política Nacional de Alfabetização (BRASIL, 2007, 2012a, 2012b, 2016a, 2016b, 2016c, 2019a) e, enquanto tal política não constituir alinhamento às dimensões de qualidade evidenciadas, a tela de Penélope continua em composição, por arranjos e desarranjos.

O coordenador pedagógico foi percebido pela política supramencionada pelo Pnaic, com participação na formação de professores e para gerir sistemas do portal eletrônico do Programa (BRASIL, 20012a, 2012b), ou seja, sem consistência específica, prescrita à função relacionada ao processo alfabetizador da criança.

Como preconizam Pinto (2011) e Soares (2011), a falta de conhecimento das próprias funções omite o profissional de atuar no campo das atividades pedagógicas, valendo-se de atender outras atividades voltadas às questões emergenciais e ou burocráticas, motivo pelo qual a identidade do coordenador pedagógico entra em confronto permanente por meio desse movimento dialético, no qual não afirma sua identidade profissional, em razão da venda de sua força de trabalho que é fragmentado e alienado, como preconiza Marx (2001), sem constituir-se na totalidade dessa função. 
O embate constitui-se na "[...] postura político-pedagógica deste profissional para o alcance de objetivos voltados para a formação integral crítica de todos os envolvidos, ou seja, alunos e professores" (VARGAS, ARANDA e DAN, 2014, p. 03).

Se tal política afirmar as atribuições legais dessas ações ante ao processo alfabetizador da criança, tendencia o esvaziamento do profissional "faz-tudo", que atenda a escola de modo generalizado, conforme estudos de Placco (2010, 2011), Pinto (2011), Soares (2011), Geglio (2011).

Entretanto, o propósito maior da ação de procrastinar para legislar com maior robustez sobre o coordenador pedagógico, está na a exploração de classes, atribuindo-lhes função burocrática concomitante à pedagógica.

\section{Considerações finais}

A Política educativa em contexto de alfabetização consubstanciada aos Programas implementados, passou a mencionar o coordenador pedagógico a partir de 2016 pelo Pnaic, evidenciando a participação desses na formação e instituição da função executora de Programas, tal como no PMAlfa, ao lhe atribuir a função burocrática de seleção, execução e monitoramento do sistema, sem mensurar a função pedagógica, como ocorre no decreto em vigência sobre a política em questão, que o integra como agente envolvido, pela gestão escolar.

A função atribuída ao coordenador pedagógico não é oficialmente constituída pela política supramencionada, entretanto, inicia-se uma demarcação concebida ao coordenador a partir do Pnaic, por meio da participação na formação docente, porém é tratada de forma incipiente, sem alinhamento ao processo pedagógico.

Aponta-se possibilidade para que outras pesquisas possam problematizar a inserção da forma pela qual esse profissional atua nas formações de docentes alfabetizadores, confluente à ausência de formação específica ao coordenador pedagógico/processo alfabetizador.

Constata-se que a política aqui delimitada, oficializa o coordenador pedagógico ao processo burocrático, seja na implementação de Programas ou pela atribuição da responsabilidade de gerir sistemas de informação, distanciando-os do processo pedagógico.

Por fim, somatiza-se a tais problematizações, condições inadequadas de trabalho, incoerência e falta de objetividade na função do coordenador pedagógico, ou seja, a exploração dessa classe, que constitui no campo da Política Nacional de Alfabetização, uma tela de Penélope. 


\section{Referências}

BRASIL. MEC. SEB. SEED. Guia Geral do Programa de Formação continuada de Professores das séries Iniciais do Ensino Fundamental. Pró-letramento. Brasília: MEC, 2007.

BRASIL. Portaria no 867, de 04 de julho de 2012. Institui o Pacto Nacional pela Alfabetização na Idade Certa (Pnaic). Ações e Diretrizes. Brasília: Diário Oficial da União, 2012a.

BRASIL. MEC. SEB. Manual do Pacto. Pacto Nacional pela Alfabetização na Idade Certa 2012. Brasília: MEC, SEB, 2012b.

BRASIL. Portaria No 1.094, de 30 de Setembro de 2016. Nova Redação dada à Portaria no 867 de 04 de julho de 2012 que institui o Pacto Nacional pela Alfabetização na Idade Certa. Brasília: Diário Oficial da União, $2016 a$.

BRASIL. MEC. SEB. Documento Orientador Pnaic em Ação 2016. Documento orientador das ações de formação continuada de professores alfabetizadores em 2016. Pacto Nacional pela Alfabetização na Idade Certa. Brasília: MEC, 2016b.

BRASIL. MEC. SEB. Boletim No 1. Pnaic/2016. Sugestões à Formação dos Coordenadores Pedagógicos: Uma Etapa de Diagnóstico e Autoavaliação. Brasília: MEC, 2016c.

BRASIL. Portaria no 04, de 04 de janeiro de 2018. Institui o Programa Mais Alfabetização. Brasília: Diário Oficial da União, 2018a.

BRASIL. MEC. SEB. Programa Mais Alfabetização. Manual Operacional do Sistema de Orientação Pedagógica e Monitoramento. Brasília: MEC, 2018b.

BRASIL. Portaria $n^{\circ} 142$, de 22 de fevereiro de 2018. Revoga a Portaria $n^{\circ}$ 04, de 04 de janeiro de 2018 que instituiu o Programa Mais Alfabetização. Brasília: Diário Oficial da União, 2018c.

BRASIL. Casa Civil. Metas nacionais prioritárias: agenda de 100 dias de governo. Brasília: Casa Civil, 2019a. Disponível em: << http://www.casacivil.gov.br/central-de-conteudos/downloads/100dias-tabela-reformatada-com-17.pdf>> Acesso em: 01 abr. 2019.

BRASIL. Casa Civil. Ofício-Circular n5/2019/COEF/DICEI/SEB/SEB-MEC, de 05 de abril de 2019. Programa Mais Alfabetização. PMAlfa. Reabertura do ciclo 2019. Brasília, Casa Civil, 2019b.

BRASIL. Decreto no 9.765, de 11 de abril de 2019. Institui a Política Nacional de Alfabetização. Brasília: Diário Oficial da União, 2019c.

BULFINCH, T. O livro de ouro da mitologia: histórias de deuses e heróis. Tradução David Jardim Júnior. Rio de Janeiro: Harper Collins, 2018.

DOURADO, L. F. (coord.) A qualidade da educaşão: conceitos e definições. Brasília: Instituto Nacional de Estudos e Pesquisas Educacionais Anísio Teixeira, 2007. 65 p. 
GEGLIO, P. C. O papel do coordenador pedagógico na formação do Professor em serviço. In: PLACCO, V. M. N. S.; ALMEIDA, L. R. O. O coordenador pedagógico e o cotidiano da escola. 8. ed. São Paulo: Edições Loyola, 2011.

LINS, C. P. D. A Função do Coordenador Pedagógico na Implementação do Pacto Nacional pela Alfabetização na Idade Certa em Escolas da Rede Municipal de Dourados/MS (2012-2017). 189 f. Dissertação (Mestrado em Educação). Programa de Pós-Graduação em Educação, Faculdade de Educação da Universidade Federal da Grande Dourados, Dourados, MS, 2018.

MARX, K.; ENGELS, F. A ideologia alemã: teses sobre Feuerbach. São Paulo: Moraes, 1989.

MARX, K. Manifesto do partido comunista. São Paulo: Cortez, 2001.

PALUMBO, D. J. A abordagem de política pública para o desenvolvimento político na América. In: SOUZA, E. C. B. M. (Org.). A avaliação e a formulação de políticas públicas em educação: leituras complementares. Brasília: MEC/UnB, 1989.

PLACCO, V. M. N. S. O coordenador pedagógico no confronto com o cotidiano da escola. In: PLACCO, V. M. N. S.; ALMEIDA, L. R. O. O coordenador pedagógico e o cotidiano da escola. 7. ed. São Paulo: Edições Loyola, 2010.

PLACCO, V. M. N. S. O coordenador pedagógico no confronto com o cotidiano da escola. In: PLACCO, V. M. N. S.; ALMEIDA, L. R. O. O coordenador pedagógico e o cotidiano da escola. 8. ed. São Paulo: Edições Loyola, 2011.

PINTO, U. A. Pedagogia escolar: coordenação pedagógica e gestão educacional São Paulo: Cortez, 2011.

SOARES, A. F. C. Coordenação pedagógica: ações, legislação, gestão e a necessidade de uma educação estética. 140f. Dissertação (Mestrado em Educação) - Universidade do Vale do Itajaí, Itajaí, 2011.

SOARES, M. Alfabetização e Letramento. $1^{\text {a }}$ reimpressão. São Paulo: Contexto, 2011. P. 15-84.

VARGAS, M. M. B.; ARANDA, M. A. M.; DAN, C. S. Atribuições do coordenador pedagógico nos imperativos legais e o enfrentamento com o cotidiano escolar. Monografia (Graduação em Pedagogia). Faculdade de Educação, Universidade Federal da Grande Dourados, Dourados, 2014.

Recebido em: 28 abr. 2019 / Aprovado em: 27 set. 2019

\section{$\underline{\text { Cite como }}$}

VIÉDES, Silvia Cristiane Alfonso; ARANDA, Maria Alice de Miranda; LINS, Cristina Pires Dias. O coordenador pedagógico subsumido à política nacional de alfabetização no entretempo 2009 a 2019: uma tela de Penélope?. Dialogia, São Paulo, n. 33, p. 60-71, set./dez. 2019.

Disponível em: https://doi.org/10.5585/Dialogia.n33.13737. 